\title{
DESCRIPTION OF TWO CASES
}

\author{
By DAVID LEES, F.R.C.S.
}

Mr. DAvid LeEs reported two cases : (I) X-ray photographs were shown of the heart and large vessels of a child ten years of age. The radiogram showed marked dilatation of the base of the heart and an aneurism of the aortic arch. The child was an inmate of the Deaf and Dumb School and was referred to him to see if anything could be done to improve the hearing. The boy was well developed and well nourished. The apex beat of the heart was one half inch outside the nipple line, and auscultation revealed an aortic systolic and diastolic murmur. Manifestations of cardiovascular syphilis were infrequent in cases of inherited syphilis ; this was possibly accounted for by the fact that children suffering from syphilitic carditis died in the earlier years of life.

(2) A series of X-rays from a patient aged fifty-three years who had been referred to him suffering from a swelling of the upper third of the tibia, which had been diagnosed as a gumma. There was a history of gonococcal infection fifteen years previously, and for seven years the patient had suffered from deep-seated pain in the leg, especially at night. Six years ago a similar swelling had occurred on the opposite leg, and was operated on for osteomyelitis. No other clinical evidence of systemic syphilis was present, and no evidence of either cardiovascular or nerve syphilis. Blood serum tests gave the following results: Wassermann reaction, weak positive; Kahn, negative; Sigma, negative. After a provocative injection of " 914 " the Wassermann, Kahn, and Sigma tests all gave negative results. The cerebrospinal fluid showed no increase of cells or globulin, a negative Wassermann reaction and negative Gold Sol test. A radiogram of the tibia and fibula showed that the condition was one of osteitis deformans. X-rays of the pelvis, skull, ribs, and other bones showed well marked Paget's disease. The case was interesting in that the original diagnosis seven years ago was at that date gumma of 


\section{DESCRIPTION OF TWO CASES}

the leg, and the pains were thought to be root pains in association with cerebrospinal syphilis. This patient's health had been maintained and there had been no advance in the bony lesions in a period of eighteen months. The treatment administered was parathyroid and calcium lactate.

The PRESIDENT said he had not found any marked lesions in children such as Mr. Lees referred to, but he had not looked for them in children under a year old. It seemed, from this case, that it was desirable to investigate quite young children. It would be found that in practically every case of inherited syphilis the bones were affected, and that when one investigated the blood vessels in such patients, especially the aorta, one might find evidence of spirochætes in the vessel walls. 